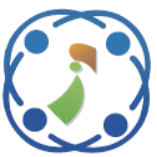

\title{
MPPT Design Using Artificial Neural Network and Backstepping Sliding Mode Approach for Photovoltaic System under Various Weather Conditions
}

\author{
Karima Boudaraia $^{1 *} \quad$ Hassane Mahmoudi $^{1} \quad$ Ahmed Abbou $^{1}$ \\ ${ }^{I}$ Department of Electrical Engineering, Mohammadia School of Engineers, \\ Mohammed V University in Rabat, Morocco \\ * Corresponding author’s Email: karima.boudaraia@ research.emi.ac.ma
}

\begin{abstract}
This paper presents a novel hybrid technique for tracking the maximum power point of the photovoltaic panel. This approach includes two loops: The first one is the ANN (Artificial neural network) loop that is used to estimate and generate the reference of optimal voltage. While, the second loop consists of the BSM (Backstepping Sliding Mode) controller. Effectively, the proposed controller is designed to track the signal of the desired voltage, which is generated using the first loop, by adjusting the duty cycle of the boost converter. Thus, this loop allows the DC/DC converter to product the maximum power at the terminals of the PV module and the load. Indeed, in contrary to the traditional backstepping, the proposed ANN-BSM technique guarantee zero steady-state error. On the one hand, by using the ANN, the system can quickly predict the desired optimal voltage, also it allows the system to avoid the unnecessary calculations and research of the maximum point of power. On the other hand, the sliding mode and the backstepping controller are used to provide the good performances and robustness against the rapid changes of insolation. In addition, the asymptotic stability of this system is made by applying the Lyapunov approach. To show the effectiveness and the tracking performances of the proposed ANN-BSM technique, a comparative study with the classical methods, $\mathrm{P} \& \mathrm{O}$ and incremental conductance algorithms, and hybrid approaches such as the ANN-Backstepping controllers and the ANN-Integral Sliding mode, is investigated in MATLAB/Simulink software.
\end{abstract}

Keywords: Artificial neural network, Backstepping command, MPPT technique, Photovoltaic module, Sliding mode controller.

\section{Introduction}

The photovoltaic energy is currently considered as an alternative of fossil energy thanks to its various advantages [1, 2]. However, the produced energy depends on weather conditions and load, which has motivated researchers to improve its energy production. In fact, the photovoltaic panels are always connected to the power converter in order to adapt their energy to the load and to optimize their efficiency.

To enable the photovoltaic (PV) panels to produce the maximum power under different meteorological conditions, the MPPT (Maximum Power Point Tracking Technique) technique is largely proposed for this purpose. This one serves to control the duty cycle of the power converter to track the maximum point of power. In fact, perturb and observe (P\&O) and incremental conductance (IC) are most used thanks to their ease of implementation [3-5]. But the major drawback of these techniques is that there is a precision-speed compromise due to the variation step of the duty cycle.

To address these issues, the non-linear commands, such as the backstepping [6] and the sliding mode [7], and the artificial intelligence controls, such as the Artificial Neural Network (ANN) [8] and the fuzzy logic [9], have been designed. Indeed, despite of the implementation complexity of these techniques, they have better performance criteria $[10,11]$. The hybrid controller, 


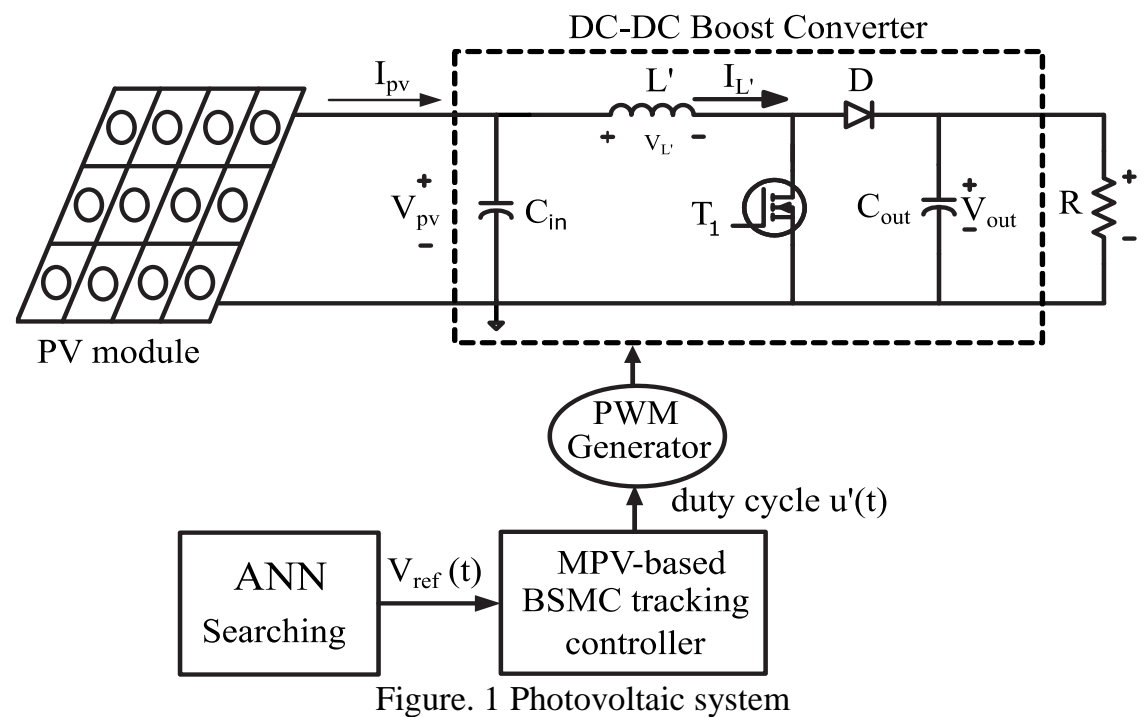

consisting of the backstepping and the $\mathrm{P} \& \mathrm{O}$ algorithm is presented in [12] to improve the system response. Indeed, the speed is improved, but there are oscillations around the maximum. In [13], authors have proposed a system composed of the artificial neural network and the backstepping control. Here, the ANN is trained to generate a voltage reference for each variation of irradiation and temperature. While, the backstepping is designed to track the generated voltage by controlling the duty cycle of the boost converter. But this technique does not allow to have a robust system under measurement errors or external disturbances.

This paper proposes a novel technique that combines between two nonlinear controllers and an artificial neural network. On the one hand, the ANN loop is applied to generate the reference signal that corresponds to the optimal voltage which consequently corresponds to the maximal power, the ANN bloc can predict quickly the desired voltage which minimizes the calculation and allows to have a rapid system response. On the other hand, the sliding mode and the backstepping control approaches are combined in this study, the main aim of this combination is to track the reference voltage that is generated by the ANN loop, the second purpose is to have a rapid, robust and accurate system under various and difficult changes of meteorological conditions. Indeed, to track the optimal voltage, the nonlinear controller is directly applied to the BOOST converter to adjust its duty cycle. The proposed technique is compared with the conventional algorithms ( $\mathrm{P} \& \mathrm{O}$ and IC) and the hybrid controllers, ANN combined with the Integral sliding mode controller [1] and ANN combined with the Backstepping controller [13], to prove its effectiveness and tracking performance.
This paper is constructed as follows, the second section presents the modelling and the description of the proposed system. The proposed controller has been well explained in section 3 , this section is dedicated also to the presentation of the $\mathrm{P} \& \mathrm{O}$ and IC algorithms. Section 4 is dedicated to discuss the simulation results. The last section is devoted to the conclusion.

\section{Proposed photovoltaic system}

This section presents the modelling of the proposed system, see Fig. 1, this one is composed of a photovoltaic module that can produce a power of 240W under the standard weather conditions (irradiation of $1000 \mathrm{~W} / \mathrm{m}^{2}$ and temperature of $25^{\circ} \mathrm{C}$ ). Then, the PV source has been connected to the BOOST converter in order to adapt the PV power to the load and to produce the maximum power for any change of insolation. In this work, the load is a resistance of $50 \Omega$.

\subsection{Modelling of photovoltaic module}

This work takes in consideration the modelling of the single diode PV cell, see Fig. 2. In fact, the PV cell modelling is well detailed in $[14,15]$. The following equation describes the current generated by a PV module:

$$
\begin{gathered}
I_{p v}=I_{p h}-I_{s}\left[\exp \left(q^{\prime} \frac{V_{p v}+I_{p v} R_{s}}{a^{\prime} N_{S} K^{\prime} T^{\prime}}\right)-1\right] \\
-\frac{V_{p v}+I_{p v} R_{s}}{R_{s h}}
\end{gathered}
$$

where $I_{p v}$ and $V_{p v}$ are respectively the current and the voltage of the PV module and $I_{s}$ is the saturation current. $q^{\prime}$ is the charge of electron, $K^{\prime}$ is the 
Boltzmann constant, $N_{s}$ is the number of cells and $a^{\prime}$ is the coefficient of ideality, this constant is usually between 1 and 1.5 and it is chosen in order to adjust the model of the PV module [16]. $R_{s}$ and $R_{s h}$ are the series and shunt resistors. $T^{\prime \prime}$ is the ambient temperature in Kelvin. $R_{s}, R_{s h}, I_{p h o}$, and $I_{s 0}$ are calculated using the parameter of electrical characteristics of the PV module (Reference: Solaria S6M2G240) and the equation presented in [14]. $I_{p h 0}$ and $I_{s 0}$ are the photocurrent and the saturation current calculated under the standard conditions.

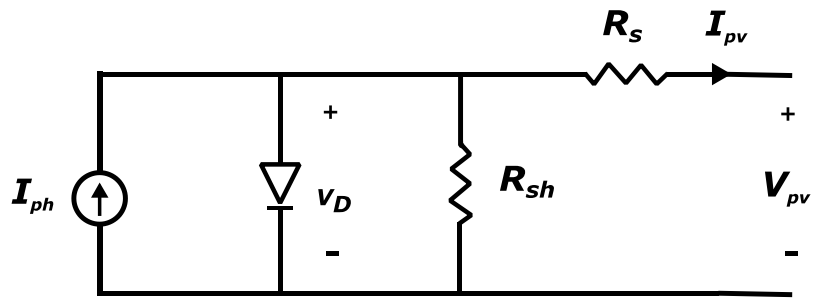

Figure. 2 Single diode PV cell

Table 1. Electrical characteristics of Solaria S6M2G240

\begin{tabular}{|c|c|}
\hline Parameters & Values \\
\hline Maximum power $\mathrm{P}_{\max }$ & $240 \mathrm{~W}$ \\
\hline Optimum voltage $\mathrm{V}_{\text {opt }}$ for $\mathrm{P}_{\max }$ & $30.05 \mathrm{~V}$ \\
\hline Optimum current $\mathrm{I}_{\mathrm{opt}}$ for $\mathrm{P}_{\max }$ & $7.99 \mathrm{~A}$ \\
\hline Maximum current $\mathrm{I}_{\mathrm{sc}}$ (Short-circuit current) & $8.49 \mathrm{~A}$ \\
\hline Maximum voltage $\mathrm{V}_{\mathrm{oc}}$ (open circuit voltage) & $37.58 \mathrm{~V}$ \\
\hline Temperature coefficient $\mathrm{K}_{\mathrm{i}}$ of $\mathrm{I}_{\mathrm{sc}}$ & $0.15 \mathrm{e}-3$ \\
\hline Number of cells in series $\mathrm{N}$ & $\mathrm{A} /{ }^{\circ} \mathrm{C}$ \\
\hline
\end{tabular}

Table 2. Calculated parameters of the adjusted PV module

\begin{tabular}{|c|c|}
\hline Parameters & Values \\
\hline Ideality Factor a' & 1 \\
\hline Series resistor $\mathrm{R}_{\mathrm{s}}$ & $0.3783 \Omega$ \\
\hline Parallel Resistor $\mathrm{R}_{\mathrm{sh}}$ & $639.7 \Omega$ \\
\hline Photo-current $\mathrm{I}_{\mathrm{ph} 0}$ & $8.495 \mathrm{~A}$ \\
\hline Saturation current $\mathrm{I}_{\mathrm{s} 0}$ & $2.196 \mathrm{e}^{-10} \mathrm{~A}$ \\
\hline
\end{tabular}

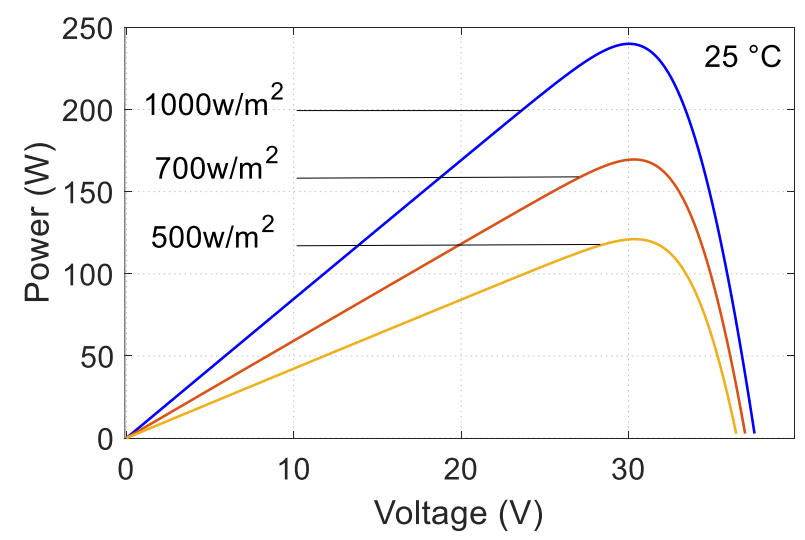

Figure. 3 Power-Voltage curves
Tables 1 and 2 show respectively the electrical characteristics of the PV module and the calculated parameters. Fig. 3 shows the P-V curves of photovoltaic module under variant meteorological conditions. As can be seen, there is a single point of maximal power and the corresponding optimal voltage changes slightly for each variation of insolation.

\subsection{Boost converter}

A DC/DC converter type boost is chosen to optimize the PV module power production. This converter allows to have higher voltage at the load terminals. The modelling of the converter is carried out in two operation sequences depending on the state of the switch $T_{1}$. The detail of modelling is explained in [15-17].

The state equation of the proposed PV system is given by:

$$
\left\{\begin{array}{c}
\dot{V}_{P V}=\frac{1}{C_{\text {in }}} I_{P V}-\frac{1}{C_{\text {in }}} I_{L^{\prime}} \\
\dot{I}_{L^{\prime}}=\frac{1}{L^{\prime}} V_{P V}-\frac{1}{L^{\prime}}\left(1-u^{\prime}\right) V_{\text {out }} \\
\dot{V}_{\text {out }}=\frac{1}{C_{\text {out }}}\left(1-u^{\prime}\right) I_{L^{\prime}}-\frac{1}{C_{\text {out }}} I_{\text {out }}
\end{array}\right.
$$

where $\mathrm{I}_{\mathrm{L}}$, is the inductor current, $\mathrm{V}_{\text {out }}$ and $\mathrm{I}_{\text {out }}$ are the output current and voltage, $\mathrm{u}^{\prime}$ is the duty cycle, and $\mathrm{L}^{\prime}, \mathrm{C}_{\text {in }}$ and $\mathrm{C}_{\text {out }}$ are respectively the boost converter inductance, input capacitor and output capacitor.

\section{Maximum power point tracking techniques}

To ensure the optimal operation of the photovoltaic panel under different weather conditions, several methods have been proposed in the literature for this purpose. The $\mathrm{P} \& \mathrm{O}$ and the incremental conductance are the most used because they are easy to implement. In addition, they do not need the large memory space for implementation. However, their major drawback is that they constantly oscillate around the maximum point of power. Also, any improvement of the follow-up speed causes the accuracy degradation because of the step size $\Delta \mathrm{u}^{\prime}$ of the duty cycle $\mathrm{u}^{\prime}$. To overcome this problem, the ANN-BSM method is designed. Indeed, this one has the better tracking performances of the MPP. 


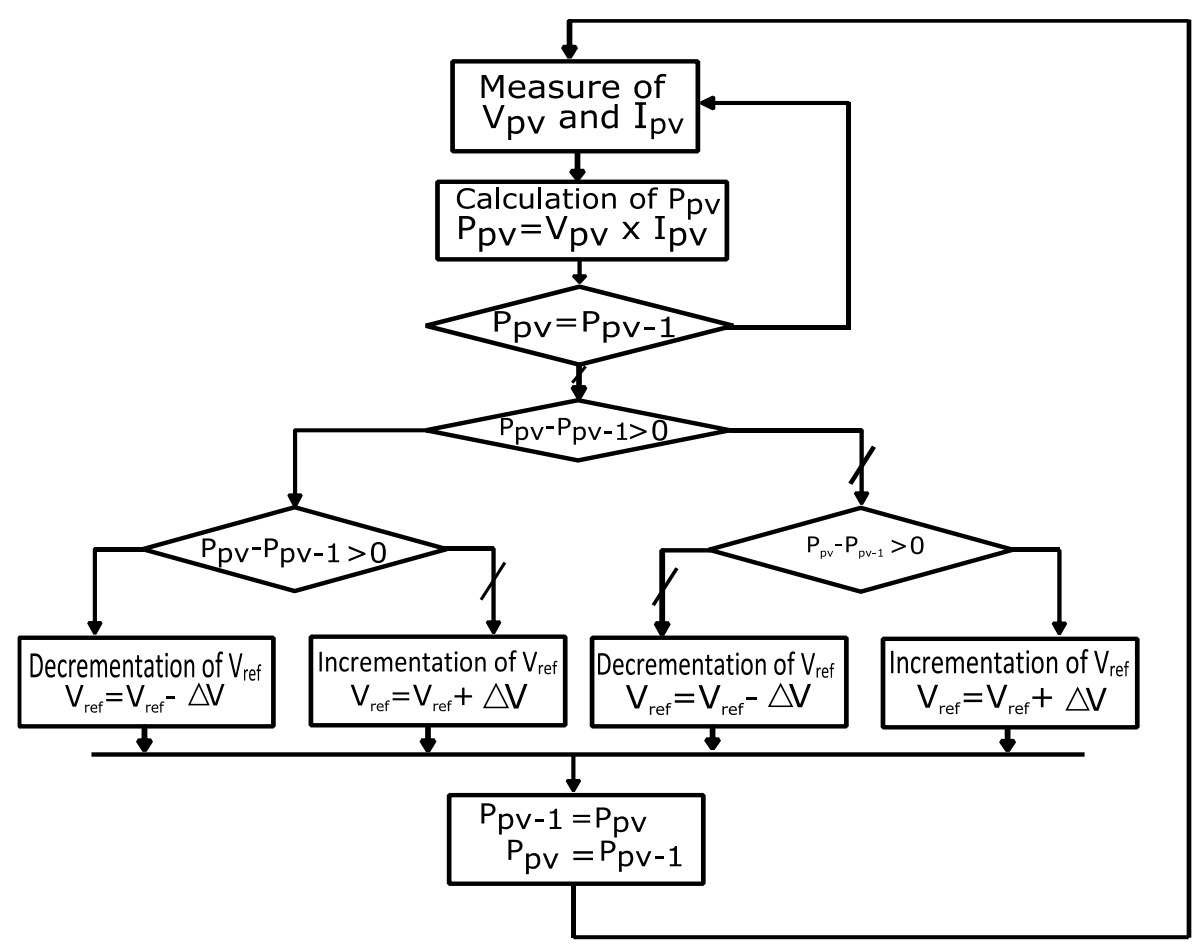

Figure. 4 Organization charts of $\mathrm{P} \& \mathrm{O}$ algorithm
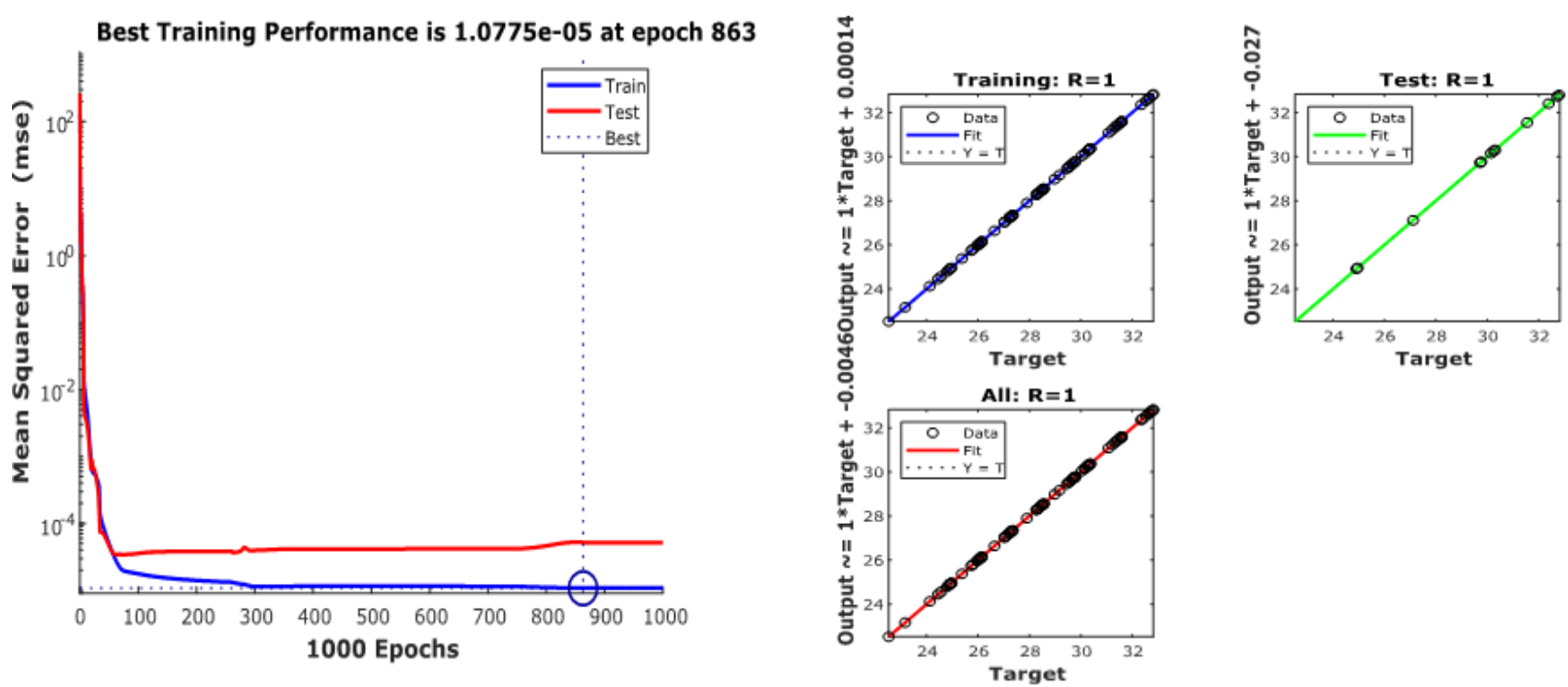

Figure. 5 Training performance, regression of training process

\subsection{Perturb and observe algorithm}

The $\mathrm{P} \& \mathrm{O}$ algorithm, depicted in Fig. 4, observes the sign of $\frac{\partial P_{p v}}{\partial V_{p v}}$. If it is positive, that means that the maximal point is in the right-hand side of the P-V curve. So, the algorithm has to slightly increasing the photovoltaic voltage by changing the duty cycle by a small step size $\Delta u^{\prime}$. While, when the sign is negative, the algorithm slightly decreases $V_{p v}$. Thus, the obtained power permanently oscillates around the maximum.

\subsection{Incremental conductance algorithm}

The incremental conductance algorithm is considered as an improvement of the $\mathrm{P} \& \mathrm{O}$ algorithm. Because this latter is not able to track the Maximum Point of Power (MPP) under the rapidly changing of insolation [18]. In fact, the incremental conductance algorithm bases on three cases on the $\mathrm{P}-\mathrm{V}$ curve. The first case, at the MPP, the slope is equal to zero. It is positive in the left-hand side and negative in the other hand side $[18,19]$. These cases are described by the following equations. 
$\left\{\begin{array}{l}\frac{\partial I_{p v}}{\partial V_{p v}}=-\frac{I_{p v}}{V_{p v}} \text { at } M P P \\ \frac{\partial I_{p v}}{\partial V_{p v}}>-\frac{I_{p v}}{V_{p v}} \text { the left hand side of } M P P \\ \frac{\partial I_{p v}}{\partial V_{p v}}<-\frac{I_{p v}}{V_{p v}} \text { the right hand side of } M P P\end{array}\right.$

with $\frac{I_{p v}}{V_{p v}}$ and $\frac{\partial I_{p v}}{\partial V_{p v}}$ are respectively the instantaneous conductance and the incremental conductance.

\subsection{Proposed method}

This section investigates the proposed technique. This one is composed of the Artificial Neural Network, the backstepping controller and the sliding mode controller. These three controllers can obtain better tracking performances. In fact, as explained previously, the ANN is trained to generate the reference of optimal voltage. This controller is learned using a database composed of 80 cases of irradiation and temperature, effectively, more the database is big more the ANN is accurate. After that, the backstepping and the sliding mode approaches are combined in order to pursue the reference voltage. The sliding mode allows to have a robust system while the backstepping controller improves the accuracy and the speed of tracking.

\subsubsection{Artificial neural network}

The ANN is inspired from the biological neuron [20]. This one can learn from the given information and convert it into knowledge. Thus, it processes like the human brain. The neuron is a unit able to perform some elementary calculations. The artificial neural network was designed by following three steps:

1. Database collection: This step is performed off-line by changing the insolation and observing the optimal voltage. Here, the inputs of ANN are the irradiation and the temperature while the output is the optimal voltage. The proposed database is illustrated in Table 3, with $T$ and $I_{r r}$ are the ambient temperature and irradiation with $V_{P V}, I_{p v}$ and $P_{p v}$ are the photovoltaic current, voltage and power.

Table 3. Database collection

\begin{tabular}{|c|c|c|c|c|c|}
\hline & \multicolumn{2}{|c|}{ Inputs } & Output & \multicolumn{2}{|c|}{} \\
\cline { 2 - 5 } & $\begin{array}{c}\boldsymbol{T} \\
\left({ }^{\circ} \mathbf{C}\right)\end{array}$ & $\begin{array}{c}\boldsymbol{I}_{\boldsymbol{r} r} \\
\left(\mathbf{W} / \mathbf{m}^{\mathbf{2}}\right)\end{array}$ & $\begin{array}{c}\boldsymbol{V}_{\boldsymbol{p} \boldsymbol{v}} \\
(\mathbf{V})\end{array}$ & $\begin{array}{c}\boldsymbol{I}_{\boldsymbol{p} \boldsymbol{v}} \\
(\mathbf{A})\end{array}$ & $\begin{array}{c}\boldsymbol{P}_{\boldsymbol{p} \boldsymbol{v}} \\
(\mathbf{W})\end{array}$ \\
\hline Case 1 & 298,15 & 1000 & 30,04 & 7,99 & 240,01 \\
\hline Case 2 & 298,15 & 900 & 30,15 & 7,19 & 216,88 \\
\hline
\end{tabular}

\begin{tabular}{|c|c|c|c|c|c|}
\hline Case 3 & 298,15 & 800 & 30,25 & 6,39 & 193,41 \\
\hline Case 4 & 298,15 & 700 & 30,32 & 5,59 & 169,60 \\
\hline Case 5 & 298,15 & 600 & 30,37 & 4,79 & 145,49 \\
\hline Case 6 & 298,15 & 500 & 30,37 & 3,99 & 121,10 \\
\hline Case 7 & 298,15 & 400 & 30,31 & 3,18 & 96,47 \\
\hline Case 8 & 298,15 & 300 & 30,15 & 2,38 & 71,67 \\
\hline Case 9 & 298,15 & 200 & 29,80 & 1,57 & 46,82 \\
\hline Case 10 & 298,15 & 100 & 28,98 & 0,77 & 22,17 \\
\hline Case 11 & 303,15 & 100 & 28,33 & 0,76 & 21,66 \\
\hline Case 12 & 303,15 & 200 & 29,17 & 1,57 & 45,77 \\
\hline Case 13 & 303,15 & 300 & 29,53 & 2,37 & 70,09 \\
\hline Case 14 & 303,15 & 400 & 29,69 & 3,18 & 94,36 \\
\hline Case 15 & 303,15 & 500 & 29,76 & 3,98 & 118,47 \\
\hline Case 16 & 303,15 & 600 & 29,77 & 4,78 & 142,35 \\
\hline Case 17 & 303,15 & 700 & 29,73 & 5,58 & 165,95 \\
\hline Case 18 & 303,15 & 800 & 29,65 & 6,38 & 189,26 \\
\hline Case 19 & 303,15 & 900 & 29,57 & 7,18 & 212,23 \\
\hline Case 20 & 303,15 & 1000 & 29,46 & 7,97 & 234,86 \\
\hline Case 21 & 313,15 & 1000 & 28,28 & 7,94 & 224,60 \\
\hline Case 22 & 313,15 & 900 & 28,39 & 7,15 & 202,95 \\
\hline Case 23 & 313,15 & 800 & 28,47 & 6,36 & 180,97 \\
\hline Case 24 & 313,15 & 700 & 28,53 & 5,56 & 158,67 \\
\hline Case 25 & 313,15 & 600 & 28,56 & 4,76 & 136,08 \\
\hline Case 26 & 313,15 & 500 & 28,54 & 3,97 & 113,22 \\
\hline Case 27 & 313,15 & 400 & 28,46 & 3,17 & 90,14 \\
\hline Case 28 & 313,15 & 300 & 28,28 & 2,37 & 66,91 \\
\hline Case 29 & 313,15 & 200 & 27,90 & 1,56 & 43,66 \\
\hline Case 30 & 313,15 & 100 & 27,03 & 0,76 & 20,63 \\
\hline Case 31 & 323,15 & 100 & 25,74 & 0,76 & 19,61 \\
\hline Case 32 & 323,15 & 200 & 26,64 & 1,56 & 41,55 \\
\hline Case 33 & 323,15 & 300 & 27,03 & 2,36 & 63,75 \\
\hline Case 34 & 323,15 & 400 & 27,23 & 3,16 & 85,93 \\
\hline Case 35 & 323,15 & 500 & 27,33 & 3,95 & 107,98 \\
\hline Case 36 & 323,15 & 600 & 27,36 & 4,75 & 129,82 \\
\hline Case 37 & 323,15 & 700 & 27,33 & 5,54 & 151,41 \\
\hline Case 38 & 323,15 & 800 & 27,28 & 6,33 & 172,71 \\
\hline Case 39 & 323,15 & 900 & 27,20 & 7,12 & 193,70 \\
\hline Case 40 & 323,15 & 1000 & 27,12 & 7,91 & 214,36 \\
\hline Case 41 & 333,15 & 1000 & 25,96 & 7,87 & 204,16 \\
\hline Case 42 & 333,15 & 900 & 26,04 & 7,09 & 184,48 \\
\hline Case 43 & 333,15 & 800 & 26,11 & 6,30 & 164,47 \\
\hline Case 44 & 333,15 & 700 & 26,14 & 5,51 & 144,16 \\
\hline Case 45 & 333,15 & 600 & 26,15 & 4,73 & 123,58 \\
\hline Case 46 & 333,15 & 500 & 26,12 & 3,93 & 102,75 \\
\hline
\end{tabular}




\begin{tabular}{|c|c|c|c|c|c|}
\hline Case 47 & 333,15 & 400 & 26,01 & 3,14 & 81,73 \\
\hline Case 48 & 333,15 & 300 & 25,80 & 2,35 & 60,59 \\
\hline Case 49 & 333,15 & 200 & 25,38 & 1,55 & 39,44 \\
\hline Case 50 & 333,15 & 100 & 24,45 & 0,76 & 18,58 \\
\hline Case 51 & 343,15 & 100 & 23,17 & 0,76 & 17,55 \\
\hline Case 52 & 343,15 & 200 & 24,12 & 1,55 & 37,34 \\
\hline Case 53 & 343,15 & 300 & 24,56 & 2,34 & 57,44 \\
\hline Case 54 & 343,15 & 400 & 24,79 & 3,13 & 77,55 \\
\hline Case 55 & 343,15 & 500 & 24,91 & 3,92 & 97,55 \\
\hline Case 56 & 343,15 & 600 & 24,96 & 4,70 & 117,36 \\
\hline Case 57 & 343,15 & 700 & 24,96 & 5,49 & 136,95 \\
\hline Case 58 & 343,15 & 800 & 24,92 & 6,27 & 156,26 \\
\hline Case 59 & 343,15 & 900 & 24,88 & 7,05 & 175,29 \\
\hline Case 60 & 348,15 & 100 & 22,53 & 0,76 & 17,03 \\
\hline Case 61 & 288,15 & 100 & 30,29 & 0,77 & 23,19 \\
\hline Case 62 & 288,15 & 200 & 31,08 & 1,57 & 48,93 \\
\hline Case 63 & 288,15 & 300 & 31,40 & 2,38 & 74,85 \\
\hline Case 64 & 288,15 & 400 & 31,55 & 3,19 & 100,70 \\
\hline Case 65 & 288,15 & 500 & 31,60 & 4,00 & 126,36 \\
\hline Case 66 & 288,15 & 600 & 31,58 & 4,81 & 151,78 \\
\hline Case 67 & 288,15 & 700 & 31,53 & 5,61 & 176,91 \\
\hline Case 68 & 288,15 & 800 & 31,44 & 6,42 & 201,72 \\
\hline Case 69 & 288,15 & 900 & 31,33 & 7,22 & 226,19 \\
\hline Case 70 & 288,15 & 1000 & 31,22 & 8,02 & 250,31 \\
\hline Case 71 & 278,15 & 1000 & 32,39 & 8,05 & 260,63 \\
\hline Case 72 & 278,15 & 900 & 32,54 & 7,24 & 235,52 \\
\hline Case 73 & 278,15 & 800 & 32,65 & 6,43 & 210,05 \\
\hline Case 74 & 278,15 & 700 & 32,73 & 5,63 & 184,22 \\
\hline Case 75 & 278,15 & 600 & 32,80 & 4,82 & 158,08 \\
\hline Case 76 & 278,15 & 500 & 32,82 & 4,01 & 131,63 \\
\hline Case 77 & 278,15 & 400 & 32,79 & 3,20 & 104,92 \\
\hline Case 78 & 278,15 & 300 & 32,66 & 2,39 & 78,03 \\
\hline Case 79 & 278,15 & 200 & 32,35 & 1,58 & 51,04 \\
\hline Case 80 & 278,15 & 100 & 31,59 & 0,77 & 24,21 \\
\hline
\end{tabular}

80 cases and a hidden layer of 50 neurons are chosen. Actually, the augmentation of the neurons number improves the training performance, as illustrated in Fig. 5. The ANN is composed of an input layer of two neurons, irradiation and temperature, and an output layer of one neuron, which is in this case the desired output voltage. To adapt the input-output, the Bayesian regularization algorithm is chosen for this purpose. This one can allow a good generalization for difficult databases, small or noisy data sets. However, it requires more computing time.

3. Training and testing the performances of the algorithm: This step is dedicated to the test of the ANN loop by find the weights that minimize a measurement error such as SSE (sum of squared errors) or MSE (mean squared errors) [21, 22]. The previously chosen algorithm minimizes the MSE which leads to the performances summarized in Fig. 5 (b).

\subsubsection{Backstepping sliding mode controller}

This controller is designed in order to track the optimal voltage. To design it, it has to define $y$ and $\mathrm{y}_{\mathrm{ref}}$ which are respectively the output and the reference signal. In this work, $y$ is the photovoltaic voltage $V_{\mathrm{pv}}$. While the reference is the ANN output that is symbolized by $\mathrm{V}_{\text {ref. }}$.

The steps for the design are as follows:

Step 1: Defining the tracking error

$$
\varepsilon_{1}=y-y_{r e f}=V_{p v}-V_{r e f}
$$

The time derivative of $\varepsilon_{1}$ is given by:

$$
\dot{\varepsilon}_{1}=\frac{I_{p v}-I_{L^{\prime}}}{C_{i n}}-\dot{V}_{r e f}
$$

The Lyapunov function candidate is:

$$
V_{1}=\frac{1}{2} \varepsilon_{1}^{2}
$$

The derivative of (6) is:

$$
\dot{V}_{1}=\varepsilon_{1} \dot{\varepsilon}_{1}=\varepsilon_{1}\left(\frac{I_{p v}-I_{L^{\prime}}}{C_{i n}}-\dot{V}_{r e f}\right)
$$

After, it has to choose the virtual control in order to stabilize the error $\varepsilon_{1}$. Here, it is symbolized by $\alpha^{\prime}$ and it is chosen equal to $\left(\mathrm{I}_{\mathrm{L}}\right)_{\mathrm{d}}$ the desired value of inductor current. $\alpha^{\prime}$ would be:

$$
\frac{I_{p v}-\alpha^{\prime}}{C_{p v}}-\dot{V}_{r e f}=-K_{1} \varepsilon_{1}<0
$$


with $\mathrm{K}_{1}>0$

Thus:

$$
\alpha^{\prime}=-C_{p v} \dot{V}_{r e f}+I_{p v}+C_{p v} K_{1} \varepsilon_{1}
$$

Step 2:

$$
\varepsilon_{2}=I_{L^{\prime}}-\alpha^{\prime}
$$

Thus, the time derivative of (10) is as follows:

$$
\dot{\varepsilon}_{2}=\frac{1}{L^{\prime}} V_{p v}-\frac{1}{L^{\prime}}\left(1-u^{\prime}\right) V_{o u t}-\dot{\alpha}^{\prime}
$$

where:

$$
\dot{\alpha}_{1}=F \dot{V}_{p v}+C_{i n} K_{1} \dot{\varepsilon}_{1}-C_{i n} \ddot{V}_{r e f}
$$

The sliding surface is defined as follow:

$$
s=\varepsilon_{1} \lambda+\dot{\varepsilon}_{1}=\varepsilon_{2}
$$

The Lyapunov function is given by the following equation:

$$
V_{2}=V_{1}+\frac{1}{2} s^{2}
$$

The time derivative of $\mathrm{V}_{2}$ is:

$$
\dot{V}_{2}=\dot{V}_{1}+s \dot{s}=-K_{1} \varepsilon_{1}^{2}-\frac{\varepsilon_{1}}{C_{i n}} \varepsilon_{2}+s \dot{s}
$$

Choosing exponential reaching law as follows:

$$
-\frac{\varepsilon_{1}}{\mathrm{C}_{\mathrm{in}}}+\dot{\mathrm{s}}=-\mathrm{g}_{1}\left(\mathrm{c}_{1} \mathrm{~s}+\mathrm{c}_{2} \operatorname{sign}(\mathrm{s})\right)<0
$$

Consequently,

$$
\begin{aligned}
& u^{\prime}=1-\frac{1}{g_{1}}\left(-\frac{\varepsilon_{1}}{C_{i n}}+f_{1}\right. \\
& -C_{i n} K_{1}\left(-\frac{s}{C_{i n}}-K_{1} \varepsilon_{1}\right)-F \frac{\partial V_{p v}}{\partial t} \\
& \left.+g_{1}\left(c_{1} s+c_{2} \operatorname{sign}(s)\right)\right)+C_{i n} \frac{\partial^{2} V_{r e f}}{\partial t^{2}}
\end{aligned}
$$

with:

$g_{1}=\frac{V_{o u t}}{L^{\prime}}, f_{1}=\frac{V_{p v}}{L^{\prime}}$ and $F=\frac{\partial I_{p v}}{\partial V_{p v}}$

Which leads to:

$$
\dot{V}_{2}=-K_{1} \varepsilon_{1}^{2}-g_{1}\left(K_{2} s^{2}+\operatorname{sign}(s) s\right)<0
$$

Therefore, that ensures the asymptotic convergence of $\varepsilon_{1}$ and $\varepsilon_{2}$ toward 0 , which consequently leads to the convergence of y toward $y_{\text {ref. }}$.

\section{Simulation results}

To show the effectiveness of the proposed technique, this one has been tested under the difficult weather conditions, as illustrated in Fig. 6, using numerical simulations on MATLAB software. In fact, during the first-time interval [0s, $0.2 \mathrm{~s}]$, the photovoltaic module is considered subjected under the standard meteorological conditions (irradiation of $1000 / \mathrm{m}^{2}$ and temperature of $25^{\circ} \mathrm{C}$ ). While, during the second time interval $[0.2 \mathrm{~s}, 0.4 \mathrm{~s}]$, the temperature increases rapidly from $25^{\circ} \mathrm{C}$ to $39.35^{\circ} \mathrm{C}$, while the irradiation remains frozen in $1000 \mathrm{w} / \mathrm{m}^{2}$. Here, it can be seen that the temperature causes a fall of power, see Fig. 6. Whereas, for $0.4<\mathrm{t}<1$, the irradiation varies slightly between two successive levels while the temperature remains frozen. In the last lapse of time, the temperature and the irradiation are quickly changed from one level to another.

The parameters of the proposed PV system and controller are as follows:

Parameters of boost converter: $C_{i n}=4700 \mu \mathrm{F}$, $L '=0.35 \mathrm{mH}, C_{\text {out }}=220 \mu \mathrm{F}, R=50 \Omega, f=2 \mathrm{Khz}$, where $f$ is the switching frequency.

The adjusted regulation parameters of the ANNBSM controller: $\mathrm{K}_{1}=10, \mathrm{~K}_{2}=10^{4}, \mathrm{c}_{1}=100, \mathrm{c}_{2}=100$.
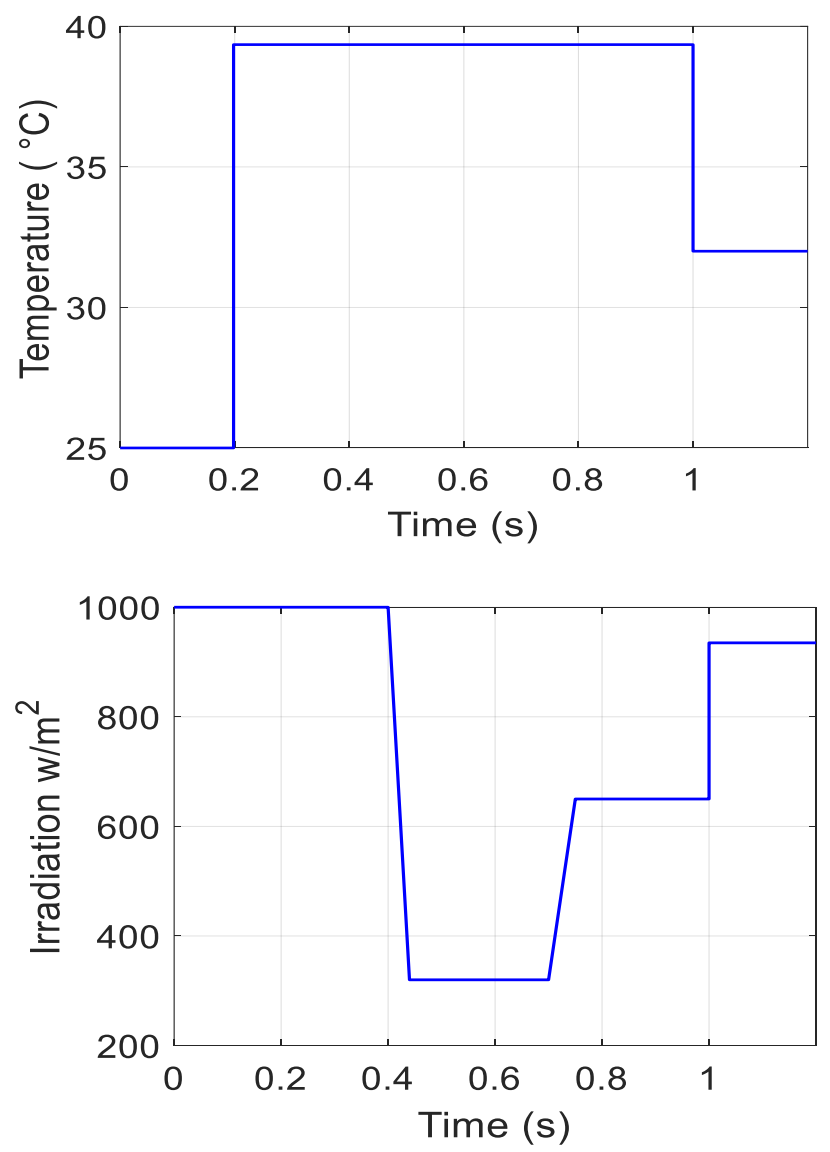

Figure. 6 Proposed meteorological conditions 


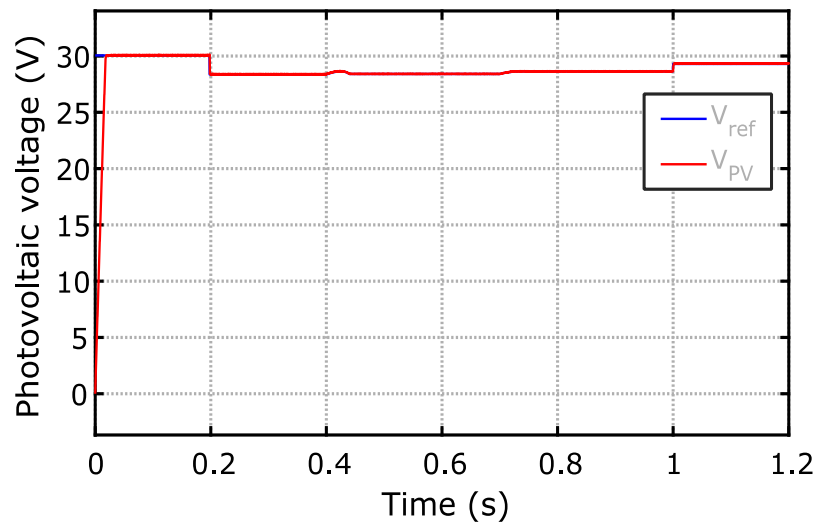

Figure. 7 The reference voltage generated by the ANN loop and the PV voltage using BSM loop

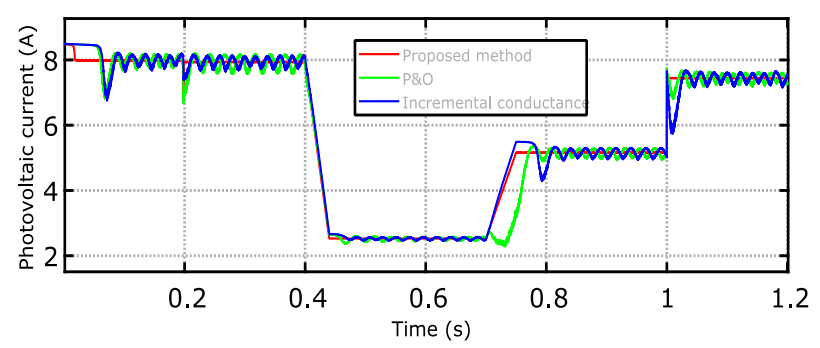

(a)

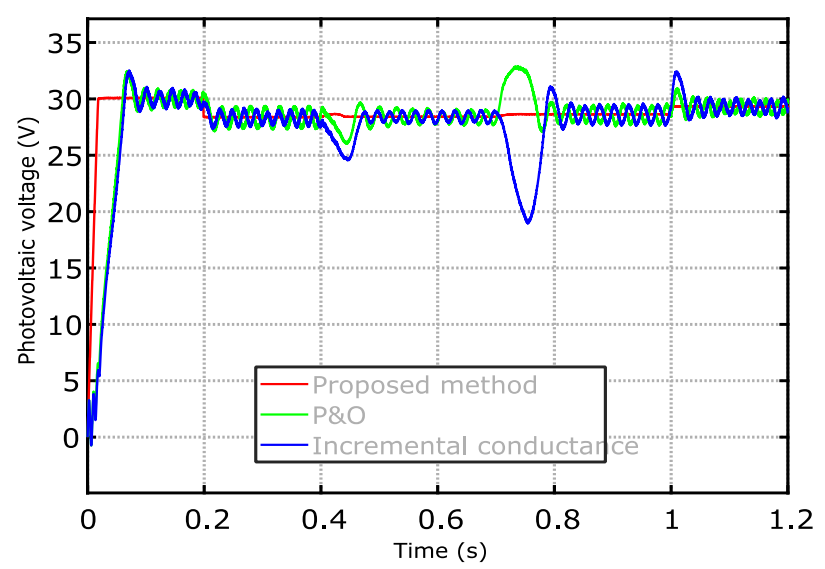

(b)

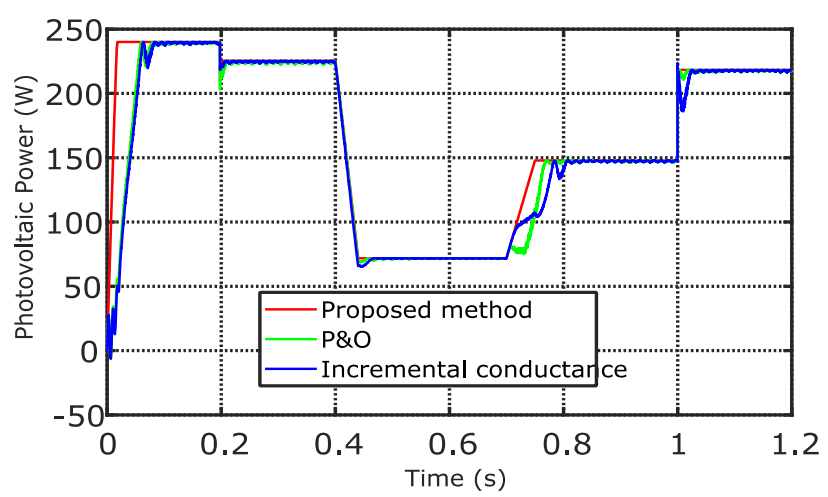

(c)

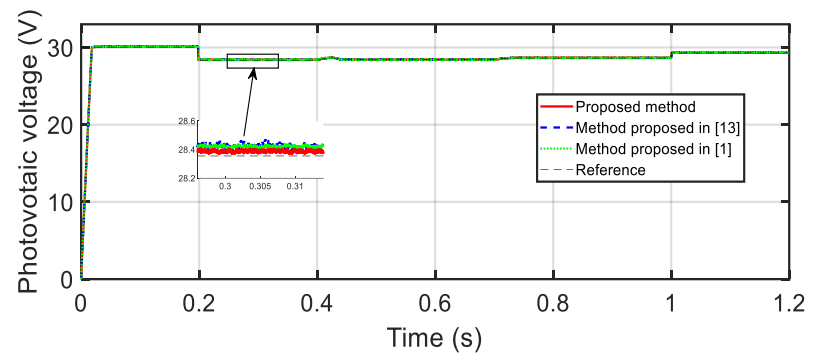

(d)

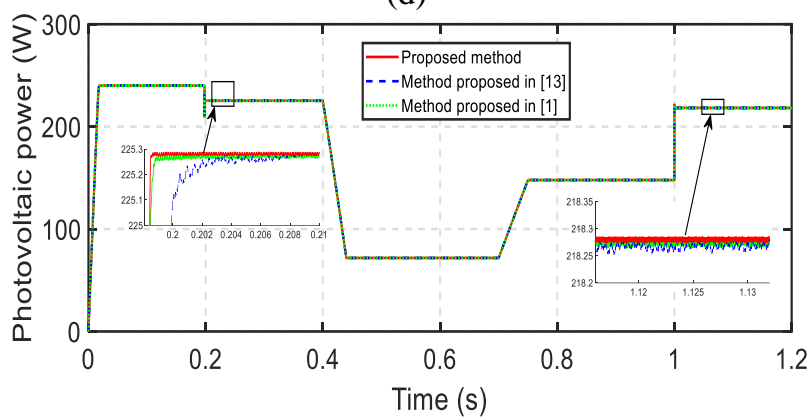

(e)

Figure. 8 PV module: a- current. b-Voltage. c-Power. Generated using the $\mathrm{P} \& \mathrm{O}, \mathrm{IC}$ and the proposed controller. $\mathrm{d}$ - voltage and $\mathrm{e}-$ power of the proposed method compared to the ANN-Basckstepping and ANN-ISMC

Fig. 7 shows the curves of the PV voltage and the reference voltage. As illustrated, the ANN generates $V_{\text {ref }}$ in the short span of time, while the BSM has rapidly tracked this reference. After comparing the tracking performances of this controller with those for the $\mathrm{P} \& \mathrm{O}$ and the IC, see Figs. 8 (a), (b) and (c), it can be seen that the proposed method is more accurate than the classical algorithms.

In order to further evaluate the performance of the ANN-BSMC strategy, a comparative with hybrid methods are given including ANNbackstepping and ANN-integral sliding mode controller respectively presented in $[1,23]$. These results are displayed in Fig. 8-d and Fig. 8 (e).

Fig. 8 (d) depicts the generated voltage by using a comparative study between the proposed approaches, the ANN-Backstepping controller and the ANN-Integral sliding mode techniques. As can be noted, the proposed method is more accurate than the other method because it tracks precisely the $V_{r e f}$. Also, as shown in Fig. 8-e, the ANN-BSMC approach is more rapid than the other techniques. Thus, the proposed technique, that is designed for controlling the power of the PV solar array, provides faster and higher responses. Consequently, the proposed ANN-BSMC achieves the MPP and best robustness against changes of the solar temperature and irradiation conditions. 


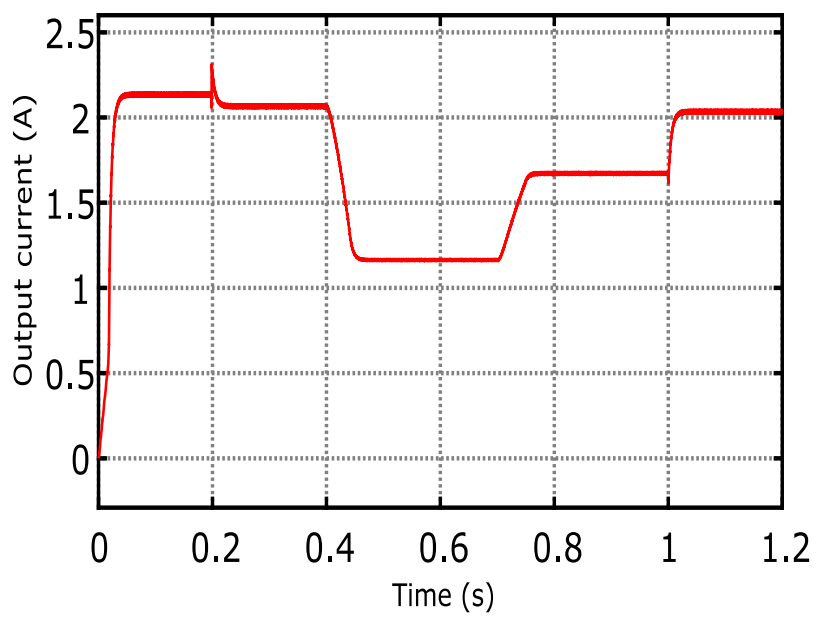

(a)

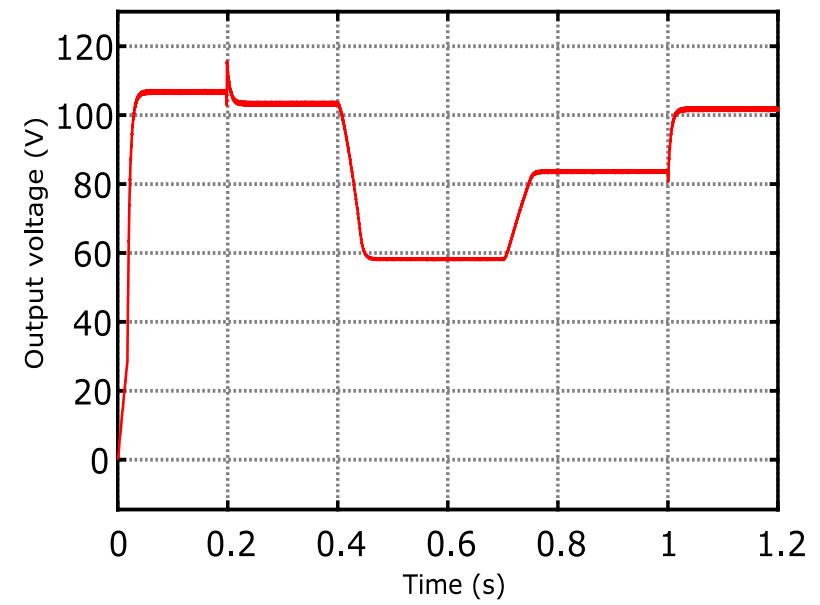

(b)

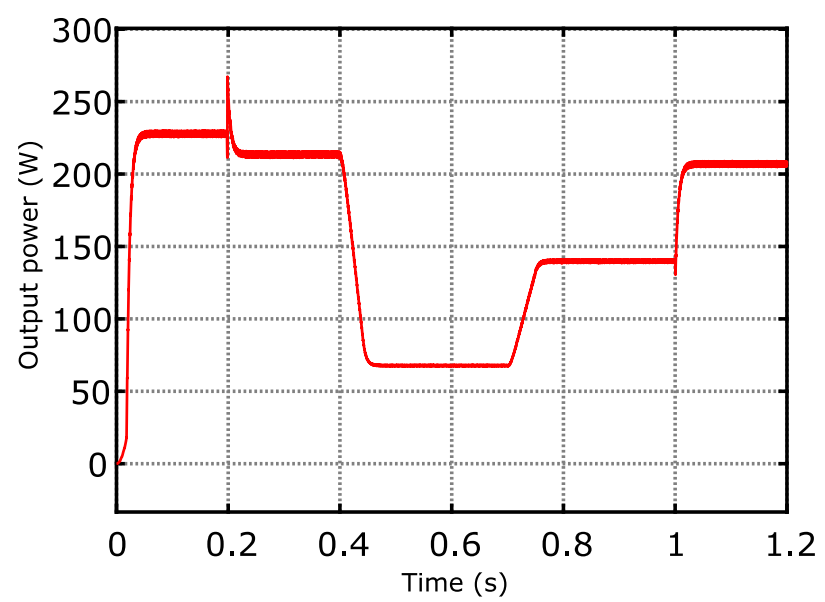

(c)

Figure 9. The output: a- current, b-voltage and c-power of the boost converter using the proposed controller

Figs. 9 (a), (b), and (c) show the output current, voltage and power of the PV module generated at the output of the boost converter using the ANNBSM controller. As can be seen, at $0.4 \mathrm{~s}$ and $0.6 \mathrm{~s}$, there is a small overshoot due to the rapid change of insolation.

\section{Conclusion}

A robust hybrid controller, composed of the backstepping and the sliding mode techniques, is proposed in this paper to improve the tracking performances of the previous MPPT techniques, this controller is robust against the external perturbations and it can pursue the reference signal under difficult and various conditions of insolation. The ANN loop is learned and trained using a big database, this one is attributed to the improvement of the system rapidity. Also, by applying this loop in the PV system, it has perfectly predicted and generated the signal of optimal voltage. Also, by using a combination of two nonlinear controllers, that are the backstepping and sliding mode controller, the system response is improved by obtaining a robust and accurate system against the rapid changes of insolation. Thus, the proposed controller can work well in place of the existing MPPT techniques.

\section{References}

[1] C. C. Ahmed, M. Cherkaoui, and M. Mokhlis, "MPPT Control for Photovoltaic System using hybrid method under variant weather condition", In: Proc. of 2019 International Conference on Wireless Technologies, Embedded and Intelligent Systems (WITS), pp. 1-5, 2019.

[2] K. Boudaraia, H. Mahmoudi, A. Abbou, and M. Hilal, "Buck converter MPPT control of a photovoltaic system", In: Proc. of 2016 5th International Conference on Multimedia Computing and Systems (ICMCS), pp. 783-787, 2016.

[3] A. Ballaji, B. P. Divakar, N. Hediyal, R. P. Mandi, and K. N. Swamy, "Energy Efficient Perturb and Observe Maximum Power Point Algorithm with Moving Average Filter for Photovoltaic Systems", International Journal of Renewable Energy Research, Vol. 9, No. 1, 2019.

[4] K. Boudaraia, H. Mahmoudi and M. El Azzaoui, "Modeling and control of three Phases grid connected photovoltaic system", In: Proc. of 2016 International Renewable and Sustainable Energy Conference (IRSEC), pp. 812-816, 2016.

[5] R. Alik, A. Jusoh, and N. A. Shukri, "improved perturb and observe checking algorithm MPPT for photovoltaic system under partial shading condition”, In: Proc. of 2015 IEEE Conference 
on Energy Conversion (CENCON), pp. 398-402, 2015.

[6] A. D. Martin and J. R. Vazquez, "MPPT algorithms comparison in PV systems: P\&O, PI, neuro-fuzzy and backstepping controls", In: Proc. of 2015 IEEE International Conference on Industrial Technology (ICIT), pp. 2841-2847, 2015.

[7] R. Pradhan and B. Subudhi, "Double Integral Sliding Mode MPPT Control of a Photovoltaic System", IEEE Transactions on Control Systems Technology, Vol. 24, No. 1, pp. 285292, Jan. 2016.

[8] S. Messalti, A. G. Harrag, and A. E. Loukriz, "A new neural networks MPPT controller for PV systems", In: Proc. of IREC2015 The Sixth International Renewable Energy Congress, pp. 1-6, 2015.

[9] C. B. Prasad, S. K. Sonam, B. R. G. Reddy, and P. Harika, "A fuzzy logic based MPPT method for solar power generation", In: Proc. of 2017 International Conference on Intelligent Computing and Control Systems (ICICCS), pp. 1182-1186, 2017.

[10] M. Mokhlis, M. Ferfra, and M. Chraygane, "Nonlinear Control of a Photovoltaic Pumping System under Partial Shading", In: Proc. of 2017 International Renewable and Sustainable Energy Conference (IRSEC), pp. 1-7, 2017.

[11] R. Khanaki, M. A. M. Radzi, and M. H. Marhaban, "Comparison of ANN and P\&O MPPT methods for PV applications under changing solar irradiation", In: Proc. of 2013 IEEE Conference on Clean Energy and Technology (CEAT), pp. 287-292, 2013.

[12] E. i. Rafika, A. Abbou, M. Mohcine, and M. Salimi, "A comparative study of MPPT controllers for photovoltaic pumping system", In: Proc. of the 9th International Renewable Energy Congress (IREC), pp. 1-6, 2018.

[13] R. E. Idrissi, A. Abbou, and M. Salimi, "Artificial Neural-Network Based Maximum Power Point Tracking for Photovoltaic Pumping System Using Backstepping Controller", In: Proc. of 2018 IEEE 59th International Scientific Conference on Power and Electrical Engineering of Riga Technical University (RTUCON), pp. 1-7, 2018.

[14] M. Mokhlis, M. Ferfra, A. Abbou, and R. El idrissi, "Robust Control for Photovoltaic
System Under Partial Shading Effect Using the SEPIC Converter", International Journal of Renewable Energy Research, Vol.9, No.2, 2019.

[15] M. Guisser, M. Aboulfatah, E. Abdelmounim, and A. El Jouni, "Nonlinear MPPT Controller for Photovoltaic Pumping System Based on Robust Integral Backstepping Approach", International Review on Modelling and Simulations (IREMOS), Vol.7, No.3, 2014.

[16] M. G. Villalva, J. R. Gazoli, and E. R. Filho, "Comprehensive Approach to Modeling and Simulation of Photovoltaic Arrays", IEEE Transactions on Power Electronics, Vol. 24, No. 5, pp. 1198-1208, 2009.

[17] M. Mokhlis and M. Ferfra, "Optimization of Photovoltaic Panels Efficiency Using a Backstepping Control Technique Under Partial Shading Conditions", International Review on Modelling and Simulations (IREMOS), Vol. 10, No.36, 2017.

[18] S. Z. Mirbagheri, M. Aldeen, and S. Saha, "A PSO-based MPPT re-initialised by incremental conductance method for a standalone PV system", In: Proc. of 2015 23rd Mediterranean Conference on Control and Automation (MED), pp. 298-303, 2015.

[19] ED. Radianto, G. M. Dousouky, and M. Shoyama, "MPPT based on incremental conductance-fuzzy logic algorithm for photovoltaic system under variable climate conditions", In: Proc. of 2015 IEEE International Telecommunications Energy Conference (INTELEC), pp. 1-5, 2015.

[20] N. Nambiar, R. S. Palackal, K. V. Greeshma, and A. Chitra, "PV fed MLI with ANN based MPPT", In: Proc. of 2015 International Conference on Computation of Power, Energy, Information and Communication (ICCPEIC), pp. 0293-0300, 2015.

[21] S. Messalti, A. G. Harrag, and A. E. Loukriz, "A new neural networks MPPT controller for PV systems", In: Proc. of IREC2015 The Sixth International Renewable Energy Congress, pp. $1-6,2015$.

[22] L. Chunyan, T. Biqiang, and C. Xiangyi, "Online Transient Stability Assessment Using Hybrid Artificial Neural Network", In: Proc. of 2007 2nd IEEE Conference on Industrial Electronics and Applications, pp. 342-346, 2007. 